\title{
CONSIDERAÇÕES SOBRE O AMBIENTE URBANO: UM ESTUDO COM ÊNFASE NA GEOMORFOLOGIA URBANA
}

\author{
Nina Simone Vilaverde Moura Fujimoto ${ }^{1}$
}

\begin{abstract}
Resumo: Este trabalho consiste em uma análise ambiental urbana que busca apreender os efeitos e respostas do ambiente ao processo de urbanização. Para isso procura, de forma integrada, conhecer a dinâmica da natureza e da sociedade e suas articulações. 0 presente estudo é realizado em uma subbacia pertencente à bacia hidrográfica do arroio Dilúvio situada na Região Metropolitana de Porto Alegre, Estado do Rio Grande do Sul. A análise engloba várias etapas: caracterização geomorfológica (morfologia original e antropogênica) e do material de cobertura superficial, análise da qualidade das águas superficiais, análise das questões sócio-econômicas pelo estudo da evolução da cobertura vegetal e uso da terra e os efeitos dos aspectos jurídicos na organização do espaço urbano. Como resultado da pesquisa, foram produzidos dados ambientais que expressam as alterações do ambiente devido ao processo de urbanização.
\end{abstract}

Palavras-chave: Geomorfologia urbana, Região metropolitana, Alteração ambiental.

\section{Introdução}

0 presente trabalho tem como objetivo principal analisar as alterações ambientais decorrentes da urbanização, através da leitura geomorfológica em uma sub-bacia pertencente à bacia hidrográfica do Arroio Dilúvio situada na Região Metropolitana de Porto Alegre, Estado do Rio Grande do Sul. A análise geomorfológica consiste na identificação e mapeamento dos compartimentos de relevo determinados por fatores naturais, originados por processos climáticos passados e atuais, quando a morfologia encontrava-se praticamente em situação original. As formas de relevo criadas ou induzidas pela atividade humana foram reconhecidas no período em que passa a ser significativa a intervenção urbana na área de estudo. Neste sentido, a avaliação geomorfológica inclui em sua análise uma abordagem histórica das formas de relevo, do material de cobertura superficial e dos processos geomorfológicos, pois revelam as dimensões das alterações ambientais no espaço urbano (FUJIMOTO, 2001).

\section{Procedimentos metodológicos e operacionais}

Para realizar este estudo fez-se necessário uma revisão bibliográfica sobre a evolução geológica da área no contexto regional; uma análise geomorfológica e uma caracterização, coletas e testemunhagens de materiais de cobertura superficial para posterior análise em laboratório.

A análise da evolução geológica esteve centrada em compreender os grandes eventos evolutivos regionais e suas consequêencias nas características litológicas e estruturais na área de estudo. A análise geomorfológica consiste na identificação e mapeamento das formas de relevo, baseados no aspecto fisionômico das formas de relevo, no seu significado morfogenético e nas influências estruturais e esculturais (ROSS, 1992). As formas de relevo decorrentes das intervenções urbanas foram classificadas em formas criadas ou construídas pelas atividades humanas e em formas induzidas pelas atividades humanas, baseadas em LIMA (1990) e DOUGLAS (1983).

A caracterização do material de cobertura superficial foi realizada a partir dos dados de sondagens realizadas pelo Departamento Nacional de Obras e Saneamento (DNOS), por ocasião da construção da Barragem Mãe d'Água, em 1957, e das análises de testemunhos e do material coletado em campo em áreas predeterminadas, obtendo-se valores de granulometria, umidade do solo, limite de liquidez, limite de plasticidade, índice de plasticidade e índice de consistência.

\section{Caracterização geomorfológica}

Em termos regionais, a área de estudo situa-se no atual Planalto Uruguaio Sul-Rio-Grandense, representado por morros e colinas que formam uma faixa alongada de direção NE-SW, predominantemente. Esses morros e colinas são formados por rochas graníticas geradas durante estágios de evolução de um cinturão orogênico, conhecido como Cinturão Dom Feliciano. 0 granito Viamão e o granito Santana são os tipos de rochas graníticas, geradas durante a formação do cinturão, que sustentam

\footnotetext{
1 Professora do Departamento de Geografia da Universidade Federal do Rio Grande do Sul.
} 
as formas de relevo da área de estudo, segundo PHILIP (1998).

0 Granito Viamão está representado na área de estudo por um relevo em padrões de colinas com vales entalhados. Esse granito apresenta uma série de características, sobretudo texturais e estruturais, que 0 identificam como uma rocha com grandes facilidades para a percolação de águas e, conseqüentemente, propício à intensificação dos processos de intemperismo e de entalhamento fluvial, os quais condicionaram a formação do relevo.

0 Granito Santana constitui o padrão em morros na área de estudo e possui uma forma alongada de direção NE-SW, sendo controlado por uma zona de cisalhamento dúctil de direção NE-SW. Sendo este granito mais novo que 0 Granito Viamão, sofreu menos as tensões tectônicas que caracterizam a formação do cinturão orogênico.

0 Planalto Uruguaio Sul-Rio-Grandense destaca-se pelos caracteres tectônicos e litológicos de sua formação e por seus diferentes graus de dissecação. Na área de estudo, o Planalto está representado por Unidades Morfológicas ou Padrões de Formas Semelhantes que são:

A) Padrão de Formas em Morros com Topos Convexos: esse padrão é formado por morros de topos estreitos convexizados e vertentes com segmentos predominantemente retilíneos e elementos côncavos com declividades médias entre 30 e $40 \%$ e entre 20 e $30 \%$, respectivamente. As altitudes vão de 80 a $100 \mathrm{~m}$, em média, até o ponto máximo cotado em $293 \mathrm{~m}$. 0 Padrão em Morros é constituído por sedimentos procedentes dos granitos, em geral alterados com pequena cobertura de material arenoso, em transição para um material tipicamente saibroso.

No Padrão de Formas em Morros observam-se cicatrizes de mineração que apresentam a rocha exposta e rupturas de declive por corte na rocha e superfícies planas criadas pela ocupação urbana através do uso essencialmente residencial. Essas superfícies planas são criadas por remanejamento dos materiais superficiais, limitadas ou não por degraus de cortes, por rupturas de declive e por rampas de aterros. O material remanejado é posteriormente transportado para outras unidades da vertente, atingindo o fundo dos vales.

Além das alterações na geometria das vertentes pela criação das superfícies planas, observa-se a impermeabilização destas áreas decorrente principalmente da compactação do material superficial para construção dos arruamentos e posteriormente das edificações. Como resultado da ocupação, ocorre a instalação de pequenos sulcos erosivos no arruamento após um evento chuvoso, principalmente em vias que acompanham o declive da vertente;

B) Padrão de Formas em Colinas de Topos Convexos e
Colinas de Topos Planos e Amplos: esse padrão é formado por um conjunto de colinas de topos convexizados e topos planos e amplos com vales bem fechados com altitudes médias predominantes entre 50 e $80 \mathrm{~m}$ e declividades médias nas classes de 10 a $20 \%$ e 20 a $30 \%$. As unidades de vertentes representadas pelas colinas demonstram uma variedade de formas geométricas, altitudes e declividades. Este padrão é sustentado por sedimentos procedentes de granitos muito alterados, representados por um material tipicamente saibroso.

Em praticamente todo o Padrão de Formas em Colinas encontram-se superfícies planas criadas pela ocupação urbana através das moradias e do sistema viário. As superfícies planas são limitadas ou não por degraus de cortes, por rupturas de declive e por rampas de aterros. 0 processo de compactação, impermeabilização e erosão neste Padrão é semelhante ao do anterior;

C) Padrão em Formas de Áreas Planas: esse padrão compreende uma série de áreas planas alveolores perfeitamente individualizadas e dispostas predominantemente ao longo dos cursos d'água, com altitudes médias entre $55 \mathrm{~m}$ a $65 \mathrm{~m}$, com declividades muito baixas. Este padrão é sustentado por sedimentos areno-síltico-argilosos decorrentes dos processos fluviais e movimentos de massa.

Este Padrão é caracterizado por setores que possuem tendência à infiltração d'água e espessamento do solo. No entanto, a ocupação destas formas ocorre através de pequenos cortes e/ou aterros na morfologia original, da impermeabilização decorrente da compactação, da edificação e da pavimentação das superfícies, acentuando-se 0 escoamento superficial, pois a impermeabilização não permite a infiltração da água no solo.

Em geral as margens dos cursos d'água que entalham os alvéolos planos encontram-se sem cobertura vegetal e com alterações em sua morfologia original em função das intervenções por moradias. Nesse caso, surgem processos erosivos por solapamento nas margens dos cursos de água e bancos de deposição de material tecnogênico nas áreas mais baixas no fundo dos vales, onde se observa a instalação de moradias sobre os depósitos tecnogênicos.

Em muitas formas de relevo em áreas planas, as intervenções antrópicas estão relacionadas às implantações de aterros e às construções de canalizações e/ou valas, pois a área encontra-se associada a períodos de inundação e situa-se dentro do nível de água máximo, onde 0 lençol freático é praticamente aflorante. 0 processo de ocupação altera 0 nível do terreno, elevando-o acima do nível natural das inundações, e modifica 0 
fluxo hídrico através da construção das canalizações e/ou valas para a drenagem das águas acumuladas;

D). Padrão em Formas de Planícies Tecnogênicas: esse padrão estende-se ao longo do arroio Mãe d'Água com altitudes inferiores a $50 \mathrm{~m}$ e forma uma extensa área plana ao longo do referido arroio, onde foi construída a barragem Mãe D’Água. Neste Padrão a ação antrópica alterou a dinâmica geomorfológica com a construção da barragem em 1957 e, posteriormente, pelo aumento da ocupação urbana.

As Planícies Tecnogênicas ocupam uma ampla área plana ao redor do lago da Barragem Mãe d'Água, formada por um intenso processo de colmatação e se estendem ao longo do arroio no qual foi construída a Barragem, proporcionando uma elevação no nível topográfico. A deposição de sedimentos é resultado, em um primeiro momento, da sedimentação lagunar e fluvial. Mais recentemente os sedimentos são provenientes das vertentes $\mathrm{e}$ transportados pelos processos fluviais. Esses materiais geralmente estão relacionados aos episódios chuvosos mais críticos, compreendendo materiais grosseiros, geralmente associados ou provenientes de atividades antrópicas. Os materiais são constituídos por cascalhos e pequenos seixos, tijolos, plásticos, papéis e vidros, reconhecidos como depósitos tecnogênicos.

Nas formas em Planícies ocorre a formação de cone de dejeção tecnogênico. Esse cone encontra-se localizado junto aos arroios no instante em que estes deságuam no compartimento de planície, proporcionando um aumento no nível topográfico. Esses cones indicam 0 grande aporte de material proveniente das vertentes por atuação dos processos fluviais.

\section{Formas dos processos atuais - morfologia antropogênica}

$\mathrm{Na}$ área de estudo foram observadas várias intervenções antrópicas sobre as formas de relevo. Estas intervenções alteraram a morfologia original, destruíram algumas de suas características básicas e geraram novos processos morfodinâmicos.

De acordo com PELOGGIA (1998), a ação humana sobre a natureza tem conseqüências em três níveis: na modificação do relevo, na alteração da dinâmica geomorfológica e na criação de depósitos correlativos comparáveis aos quaternários (os depósitos tecnogênicos) devido a um conjunto de ações denominada tecnogênese.

As modificações no relevo proporcionam o surgimento de formas de relevo tecnogênicas decorrentes de processos criados ou induzidos pela atividade humana que correspondem essencialmente ao sexto taxon, segundo a classificação proposta por ROSS (1992). Esse taxon engloba as formas menores produzidas pelos processos morfogenéticos atuais e quase sempre induzidos pela ação humana, como os sulcos erosivos, os cones de dejeção tecnogênicos e as cicatrizes de solapamento; ou as pequenas formas do relevo que se desenvolvem por interferência antrópica ao longo das vertentes, como os cortes e os aterros. No entanto é possivel verificar as conseqüências da ação humana no quarto taxon, isto é, na formação de formas de relevo individualizadas dentro de uma unidade morfológica ou padrão de forma semelhante. Este é o caso das Formas em Planícies Tecnogênicas

A modificação do relevo promove a criação, indução, intensificação ou modificação dos processos geomorfológicos. De acordo com a tipologia e 0 estágio de alteração, pode-se descrever algumas atividades antrópicas que geram novos padrões de comportamento morfodinâmico:

A. A eliminação da cobertura vegetal e as modificações através de cortes e/ou aterros elaborados para a execução dos arruamentos e moradias acabam por alterar a geometria das vertentes, aumentando a declividade e expondo 0 material anteriormente protegido da ação direta dos agentes climáticos;

B. Os arruamentos, mesmo respeitando a topografia, acabam cortando e direcionando os fluxos hídricos, gerando padrões de drenagem não existentes. As ruas transformam-se em verdadeiros leitos pluviais durante os eventos chuvosos, canalizando e direcionando os fluxos para setores que anteriormente possuíam um sistema de drenagem diferente;

C. A impermeabilização modifica o fluxo da água, tanto na superfície como em profundidade. As superfícies impermeabilizadas não permitem a infiltração da água no solo, assim como a circulação de ar e água;

D. As canalizações de águas pluviais existentes nas moradias acabam por mudar a direção do fluxo natural das águas das chuvas ou das águas servidas;

E. Os aterros recobrem a vegetação original e os materiais de cobertura superficial de formação natural, criando áreas de descontinuidades entre materiais heterogêneos, além de elevarem altimetricamente a superfície original, alterando sua declividade.

A criação de depósitos correlativos representados pelos depósitos tecnogênicos representa o terceiro nível de conseqüências da ação humana sobre 0 meio natural. Esses depósitos evidenciam um ciclo de erosividades sobre a massa erodível (AB'SABER, 1990 in: PELOGGIA, 1998). Os depósitos tecnogênicos são correlativos aos processos relacionados às formas humanas de apropriação do relevo, e sua época de existência caracteriza um tempo geológico/histórico distinto. 


\section{Considerações finais}

Com base no trabalho desenvolvido entende-se que a análise geomorfológica concebida permitiu apreender alguns dos principais efeitos e respostas do ambiente decorrentes do processo de urbanização na área de estudo. A ação antropogenética vem alterando a dinâmica natural da área de estudo, contribuindo na intensificação dos processos de vertentes, fluviais, de escoamento concentrado e de assoreamento.

Com isso, pode-se afirmar que, em linhas gerais, as alterações ambientais na área de estudo correspondem a modificações muito significativas na morfologia original e na dinâmica dos processos geomorfológicos, de forma a intensificar suas potencialidades naturais. Contudo, não trouxeram a essa bacia hidrográfica quadros severos de degradação ambiental associados a riscos de natureza geológica, geomorfológica e hidrológica que coloquem em perigo a vida da população. No entanto, a intensificação dos processos de erosão e deposição provocaram a criação de novas formas de relevo associadas aos depósitos tecnogênicos. Esses fatos, associados aos ambientes de ocupação inadequada, promovem o surgimento de áreas com elevado comprometimento da qualidade ambiental.

No mais, este texto cumpre a função específica de introduzir um problema e estimular estudos de casos concretos. 
FUJIMOTO, N. V. M. (2005). On urban environment: a study focusing urban geomorphology. Revista do Departamento de Geografia, n. 16, p. 76-80.

Abstract: This work consists of an urban environment study in a sub-basin of Dilúvio stream's hydrographic basin located in Porto Alegre City Metropolitan Region, state of Rio Grande do Sul, Brazil, for apprehending the effects on and responses of the environment to the urbanization process in such area. Accordingly, a comprehensive knowledge of nature and society dynamics and how they articulate is envisaged. The environmental analysis is divided into the following stages: geomorphologic and superficial covering material characterization (original and anthropogenic morphology); analysis on the socioeconomic features from the study on the vegetal covering and soil use evolution and effects of the juridical aspects on the urban space arrangement. As a result of the research carried out, environmental data expressing the changes on the environment caused by urbanization processes were generated.

Key words: Urban geomorphology, Metropolitan region, Environmental change.

Recebido em 7 de setembro de 2005, aceito em 2 de outubro de 2005.

\section{Referências}

DOUGLAS, I. (1983) The Urban Environment. London, Edward Arnold. $229 \mathrm{p}$.

FUJIMOTO, N.S.V.M. (2001) Análise Ambiental Urbana na Área Metropolitana de Porto Alegre-RS: Sub-bacia Hidrográgica do Arroio Dilúvio. Tese de Doutoramento, Departamento de Geografia, Faculdade de Filosofia, Letras e Ciências Humanas, Universidade de São Paulo. 236p.

LIMA, C.R. de (1990) Urbanização e Intervenções no Meio Físico na Borda da Bacia Sedimentar de São Paulo: uma abordagem geomorfológica. Dissertação de Mestrado, Departamento de
Geografia, Faculdade de Filosofia, Letras e Ciências Humanas, Universidade de São Paulo. 70p.

PELOGGIA, A. (1998) O Homem e o Ambiente Geológico: geologia, sociedade e ocupação urbana no Município de São Paulo. São Paulo, Xamã. $271 \mathrm{p}$.

PHILIP, R.P. (1998) A Evolução Geológica e Tectônica do Batólito Pelotas, RS. Tese de Doutorado. Instituto de Geociências, Universidade de São Paulo. $371 \mathrm{p}$.

ROSS, J.L.S. (1992) 0 Registro Cartográfico dos Fatos Geomorfológicos e a Questão da Taxonomia do Relevo. In: Revista do Departamento de Geografia 6. São Paulo FFLCH/USP. 17-29 p. 